\author{
1985 PARTICLE ACCELEPATOR CONFERENCE \\ Accelerator Englneering and Technology \\ Vancouver, British Columbia \\ May 13-16, 1985
}

\title{
DISCLAIMER
}

This report was prepared as an account of work aponsored by an agency of the Unitod States Government. Nelther the United States Government not any arency thereof, nor any of their omployees, makes any warranty, express or Implied, or assumes any legal liabillity or responslblilty for the accuracy, completeness, or usefulness of any information, apparatua, product, or procas diecloes, or represents that lts use would not infinge privalely owned rights. Referonce hereln to any upecifle commercial product, process, or service by trade name, trademark, manufacturur, or otherwise does not necosaarlly constitute of imply lis ondorsement, recommiondation, or favor, ing by the United Staten Government or any agency thereof. The views and opinions of authors expreseed herein do not necessarily state or rofloct those oi the United Statea Government or any atgency thereof.

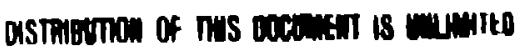
LOS AlaIMOSS LosAlamos Nationalaboratory 


\section{ACCELERATOR COLUMN MODELS FOR LOW-CURRENT BEAMS*}

D. P. Rusthot, Paul Allison, R. R. Crandall, AT-2, MS H818

Los Alamos National Laboratory. Los Alamos. MM 87545 USA

\section{Sumary}

This paper describes three analytic approaches used to model electrostatic accelerator columns ii beam-transport code: for low-current beams and compares the results of each approach with the results obtained by numerically calculating the electric field based on charge distribution on equipotential surfaces. The three analytic approaches described are (1) a cubic energy-gain approximation, (2) a cubic longitudinal electric-field approximation, and (3) the aperture equation. The first two approaches calculate impulse approximations at the apertures, whereas the third is an integration of particle trajectories through the column field. The conditions under which the solutions tend to break down are discussed.

\section{Introduction}

We infect a $20-\mathrm{kV} \mathrm{H}^{-}$bean into an $80-\mathrm{kV}$ accelerating column on the LOS Alamos acrelerator test stand (ATS). The column has a length/aperture rat10 (L/Ra) of approximately 2 for the accelerating portion and an $L / R_{a} \sim 1$ for the electron suppressor. Our purpose for examining the analytical models discussed here was to determine which one best represented the ATS accelerator column. We calculated the beam dynamics as a function of $L / R_{a}$ for energy gain factois of 5 and 25 to compare results for these models. We assumed the beam did not significantly alter the charge distribution on the coldmn electrodes.

Two of the models described use a thin-lens (TL) impulse modeling techntaue (Fig. 1). The column entrance and exit apertures apply focusing and defocusing impulses, respectively, and between these apertures is a linear energy gain. The difference between the two impulse models is the derived value of the electric fleld potential at each lens that is used to calculate the impulse approximation. The third model described uses the well-known aperture formula, 1 reu. resenting the column flelds by superimposing the potentials calculated by the aperture formula at the column entrance and exit (F1g. 2).

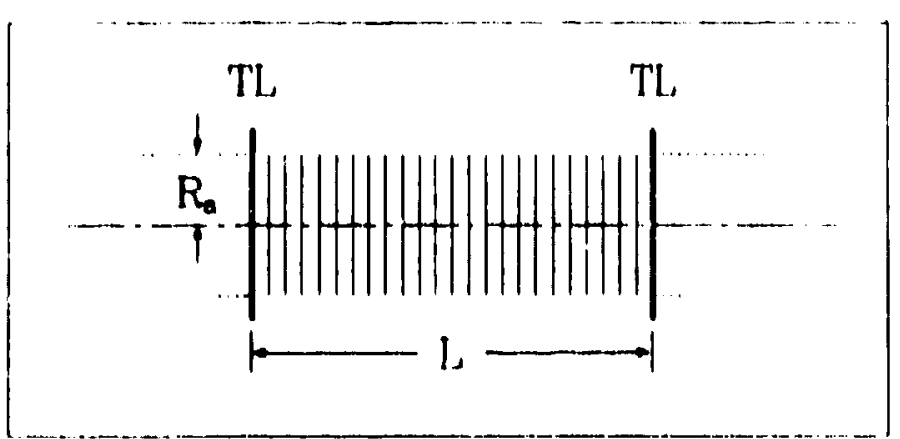

Fig. 1. Thin lens impulse column model. (equipotentlal lines shown)

We compared the transformation matrices fon each of the models at the two eneray-gain factors with

*Work supported by the US Dept, of Defense, Defense Advanced Research Proje ts Agency, and Balitstic M1sstie Defense Advanced Technology Center.

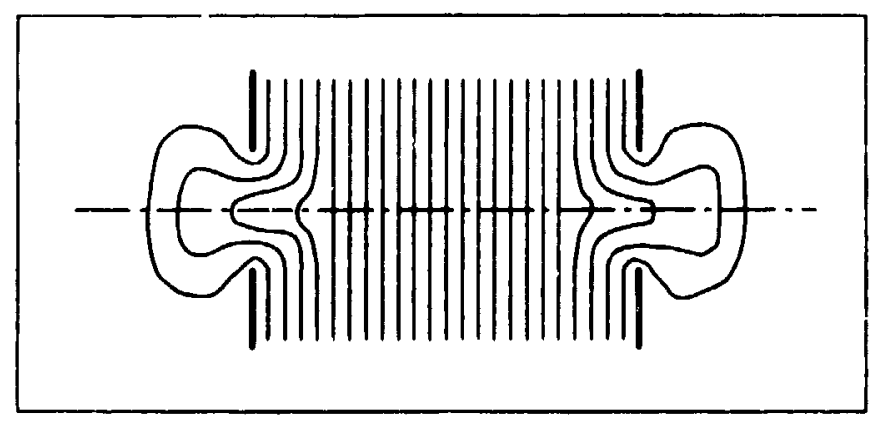

F1g. 2. Superposition of apertures column model. (equipotentfal lines shown)

range of $L / R_{a}$ ratios. To check the validity of these models, we used the program CHARGE $-20^{2}$, which can calculate electric flelds of an arbitrary set of -ylindrical electrodes by first computing the charge distribution on the surfaces. By calculating the motion of two particles through the flelds near the column, an equivalent transfer matrix was constructed in both CHAPS,F-2D and the aperture model

\section{Cubic- - Mode 1}

The cubic- $\phi$ model approximates the energy gain liear the aperture with a cublc between $z=0$ and $z$. $3 k R_{a}\left(R_{8}\right.$ - aperture radius, $k$ = a multiplicative constant) with the plane of the aperture at $z=2 K R_{\text {. }}$ $($ ( 19.3$)$. This model is used in computer codes SPEAM" and TRACE 4, with the constant $k=1$. The cublc energygoin functic.n gives us the following expression:

$\phi(z)=\phi_{0}+\left(\frac{z}{3 K R_{a}}\right)^{3} k R_{a} \Delta \Phi / L$.

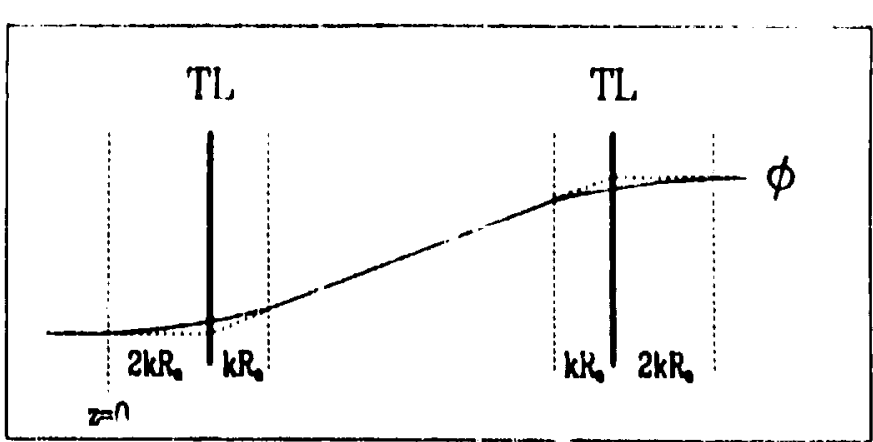

F1g. 3. Cubte energy-gain function through an accelerator column.

where $\phi_{0}$ is the potentiol at the column entrance and $\Delta \phi$ is the energy change through the column. By calcu. lating the radial force, the change in transvelse momenta and the average velocity near the aperture, and by traating this result as the effect of a thin iells. the entrance apcirture focal length becomes

$\frac{1}{f}=\frac{\Delta \phi / L}{\left(\phi_{0}\right)^{1 / 2}} \frac{\left.\Delta \phi_{0}+0.25 k R_{0} \Delta \phi / L\right)^{1 / 2}}{\omega^{2}}$

with simllar expless fon for the iocol length at the column exte. Because the longttudinal electric fleld 
$E_{2}$ is given by $2 / 3 z$ and the radial electric field $E_{r}$ is proportions 1 to $a E_{z} / a z, E_{r}(z)$ becemis 1 inear in the region of the aperture, which does not appear to be very realistic.

\section{Cubtc $-E_{\text {: }}$ Mode 1}

In this model, the longltudinal fleld on-axts near each aperture is approxtmated by a cublc function that makes a smooth transition between the constant fields $E_{1}$ and $E_{2}$ on the two sides of the dperture (Fig. 1). If the cubte extiends a distance $k R_{a}$ cn each side of the aperture, then

$E_{2}(z)=\frac{E_{1}+E_{2}}{2}+\frac{E_{2}-E_{1}}{4}\left[3\left(\frac{2}{K R_{a}}\right)-\left(\frac{2}{K R_{a}}\right)^{3}\right]$,

$-k k_{\mathrm{a}} \leq z \leq k R_{\mathrm{a}}$.

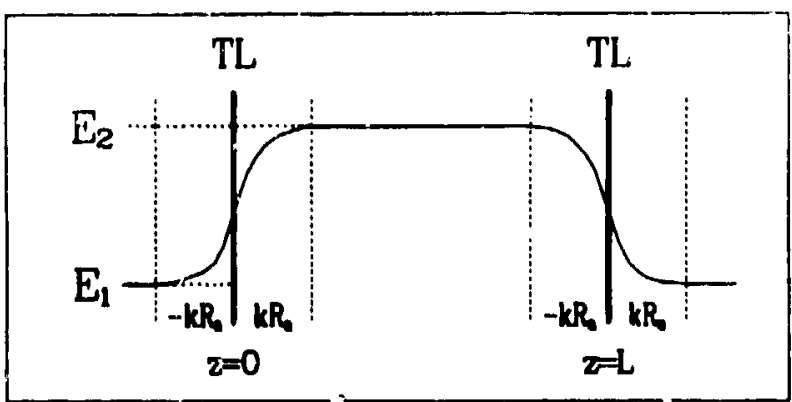

Fig. 4. Cublc longitudinal electric lield function through an accelerator column.

If we let $E_{1}=0$ and $E_{2}-\Delta \phi / L$, we obtain o simflar expression for the entrance focal length:

$\frac{1}{f}=\frac{\Delta \ell / L}{4\left(\phi_{0}\right)^{1 / 2}\left(\phi_{0}+6.3 K R_{a} \Delta \phi / L\right)^{1 / 2}}$.

With this model, Er(z) near the aperture is parabollc with $z$ and perhaps more reallstic than the prevlous mode 1 .

\section{SAF Model}

The potential distribution produced by an accel erating-column gap may lso be opproximeted by using - Superposition of Apertures formula (SAF). The potential distribution produced by a conduiting aperture plate separaing two regions. Which have asymptotic unfform fields $E_{i}(-\infty)$ and $E_{2}(+\infty)$, is well known.2 For plate at zero potentlal located at $z=0$, the potential distrivution on axis is glven bu

$\phi(2)=-\left(E_{1}+E_{2}\right) \frac{z}{2}+\left(E_{1}-E_{2}\right) \frac{2}{2} \tan ^{-1} z / R_{0}$.

For two or more apertures, superposition would be expected to valtd for $L / R_{a}>>l$, where $L$ is the seperation of the apertures. ejp two apertures at potentlal $\pm V / 2$ locatad at $\pm L / 2$ and w/th $E( \pm \omega) \cdot 0$, the on-axis potential distribution is then given by the SAF:

(2) $-\left(R_{a} V / L \pi\right)\left(U_{+} \tan ^{-1} U_{+} \cdot U_{-} \tan ^{-1} U_{-}\right)$.

whore $U_{t}=(2 \pm L / 2) / R_{a}$.

\section{Models Conpared}

A comparison of these models was nade by calculating the transfer matrices through each column mode at $L / R_{a}$ ratios ranging from 0.1 to 1000 . Because the transfer-matrix calculations for the different models involved different physical lengths (vory large for the SAF mode1). the matrices were multiplied by fore and aft negatlve drifts (as required) to make the equivalent length equal to $L$ in all cases. The main differences in the transfer matrices were found in element $R_{21}$. Which represents the focusing strength of the column. The values were normalized to the column length ard plotted against the $L / R_{a}$ ratio, as can be seen in Figs. 5 and 6 , corresponding to the two energygain factors $G$ (output/input energles) of 5 and 25 .

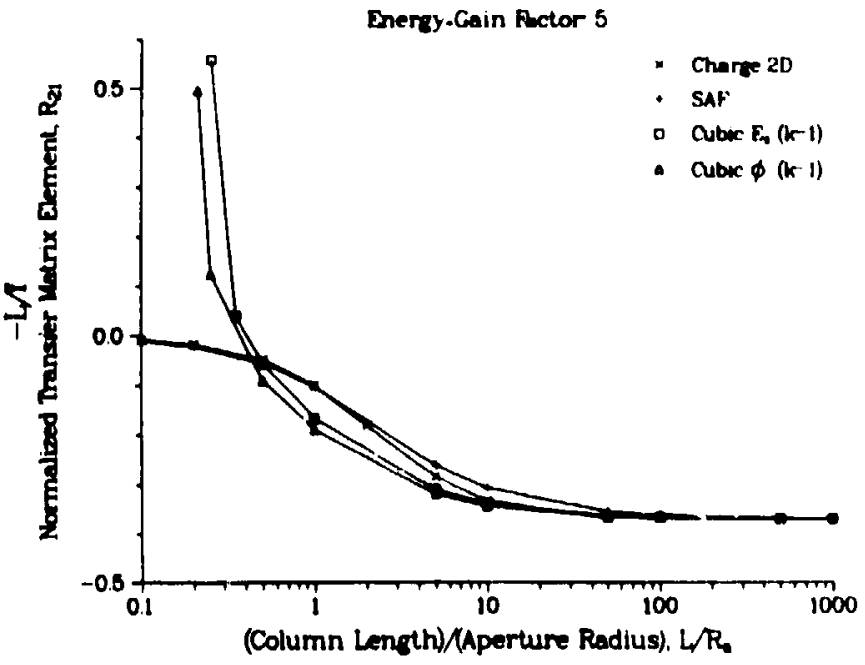

Fig. 5. Column models compared ( $G=5, k=1)$

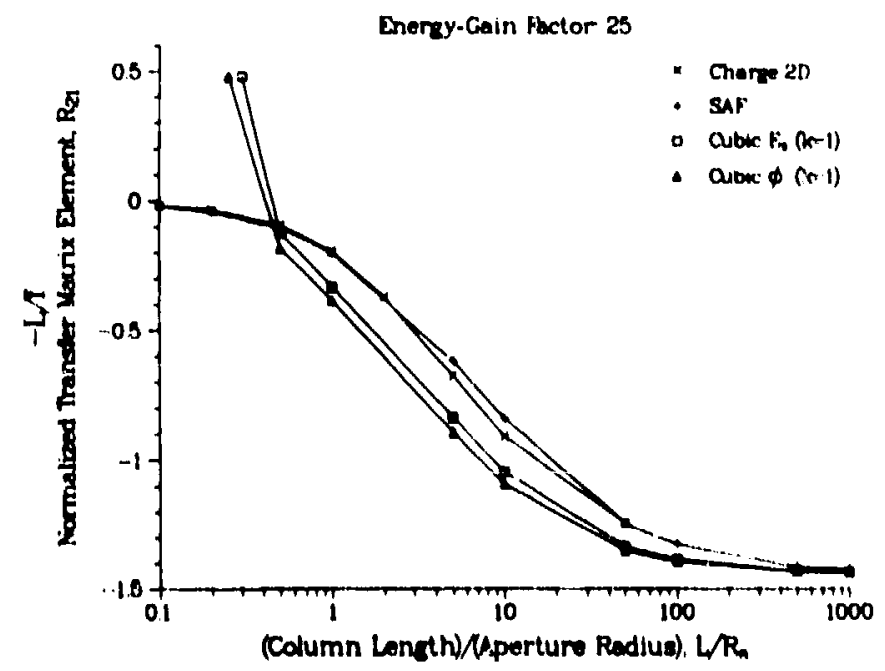

F1g. 6. Column models compared (G-25, $k=1)$

The SAF model appears to be the most accurate of the three, following the CHARGE-2D numerical calculation fairly closely. (Hote that the SAF cannot take Into account the electrode thicknuss, which is essent lal in the CHARGE-20 calculation.) The thin-lens impulse models both show slaniflcont depertures from the CHARGE-2D curve, notably in the ares of interest to us where $1 \leq L / R_{0} \leq 2$, and where the difference is as much as a factor of 2 . However, if the multiplicatlve factor $k$ in both impulse mocels is set equal to 1.8 Instead of 1.0. we find reasonable concurrence between all column models in the $L / R_{a}$ range $>1$, as can be seen In Flos. 1 and 8 . 


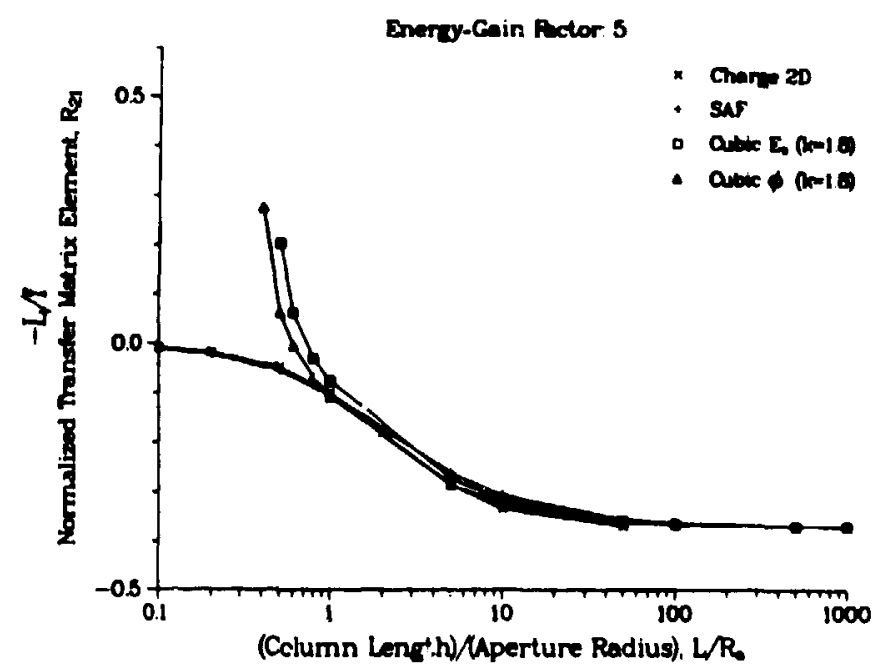

Fig. 7. Column models comparsd $(G=5, k=1.8)$

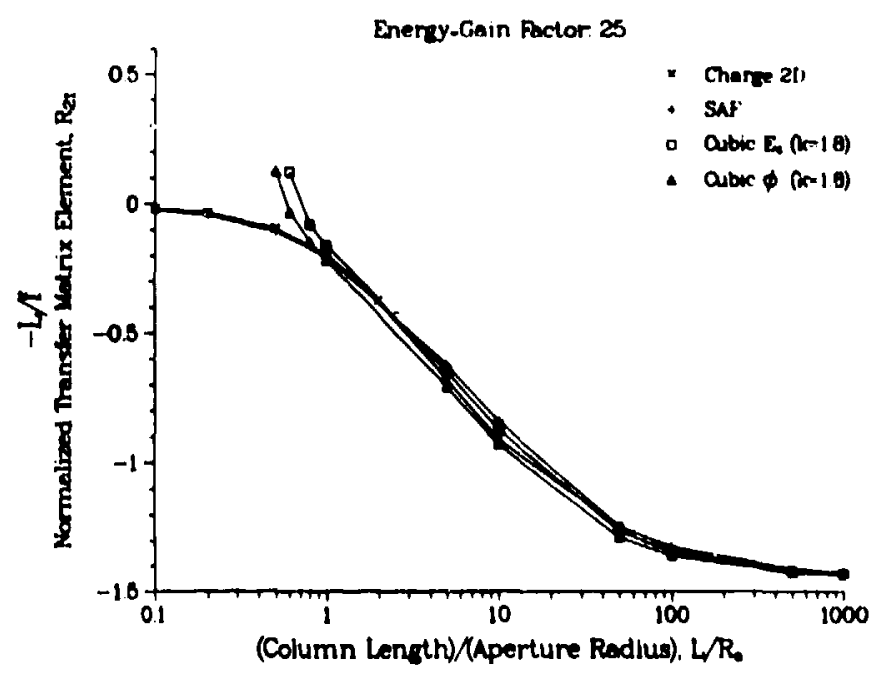

Fig. B. Column models compared $(G=25, k=1.8)$

\section{Limiting Cases}

For the two impulse models, the formulation breaks down in the 11 mit os $L / R_{a} \rightarrow 0$, and, thus, this 1 imiting case cannot be calculated. For the SAF model, as $L / P_{a} \rightarrow 0$, we obtain

$\phi(z)+V / \pi\left[\left(\operatorname{Tan}^{-1} U+U /\left(1+U^{2}\right)\right]\right.$, where $U=z / R$.

Moanwhlle, the exact solution for $L=0$ can be ob talned analytically, and the result is

$\phi(r, z)=v\left[1-\int_{f}^{x} e^{-x|U|} J_{j}(x) J_{0}(x r / R) d x\right]$.

with the on-axts potentlal then given by

* We are indebted to Ricliard $K$. Cooper for ass istance in solving this problem. Thls solution can also be derlved from Ref. 1, p. $489,490$. $\phi(z)=(v / 2) u / \sqrt{u^{2}+1}$

The transfer matrices for thase two $L=0$ cases were calculated and comparad [Eqs. (7) and (8)], resulting in an asymptotic limit for R21 in the SAF nodel that was larger by 38 anc $17 \%$ for the energyga in factors of 5 and 25, respectively, when compared with the exact solution. Thus, it appears that sigifficant error in the SAF modei exists in the limit $L \rightarrow 0$, although it gives very reasonable results, even to very smait $L / R_{a}$ ratios $(-0.1)$.

In the 1 imit as $L / R_{a} \rightarrow \infty$, the crarsfer-matrix elemerts $R_{21}$ of each of the three models were in excellent agreement with $R_{21}$ of the analytical formula. based on a unform accelerating fleld between two apertures of vanishingly small radius:

$R_{21}=\frac{3}{8}\left(\frac{G-1}{G L}\right)(1-\sqrt{G})$

where $G$ represents the energy gain factor. For each indel at an $L / R_{a}$ ratic of 1000 . agreement was within $1 x$ of the value calculated using the above formula.

\section{Concluston}

We found that the analytical impulse models as they are used in computer codes TRACE and SPEAM are both limited and inaccurate over a wide ranye. When a multiplicative factor $k$ of 1.8 was introduced into these models, reasonable agreement with the numertcal calculations of CHARGE-20 was demonsirated for $\mathrm{L} / \mathrm{K}$ ratios $>1$. For $L / R_{a}$ ratios $<1$, these models cannot be used.

The SAF model works for the entire range of $0.1 \leq L / R_{a} \leq 1000$. The aperture formula modeled the flelds near the apertures very well, even when two apertures were used and superposed to represent a column as is the case in the SAF modei. We have, therefore, found an analytical model that is buth acceptably accurate over the wide range of $L / R_{a}$ ratius and rapable of modeling multlelectrode columns and einzel lerses as woll.

Aga in, these results are valld only for lowcurrent beams. We plan to modify TRACE to include the aperture formula and to update our version of SPEAM to include the multiplicative factor of $k=1.8$.

\section{References}

1. See for example, irnst Weber. "E lectromagnetlc Theory," Dover Publications, Now York, 1965, p. 431.

2. K. R. Crandall, "Computation of Charge Olstribution on or near Equlpotentlal surfaces," Los Alamos Sclerit if te Laboratcry Report LA-3512 (December 1966).

3. W. Joho, "SPEAM, A Comiouter Program for Space Charge Beam Envelopes," TRIUMF, Design Note TRI-ON-73-11, (March 1973).

4. K. R. Crandall and D. P. Rusthol, "Documentation for TRACE: An Interactive Beam-Tiansport Code". Los Alamor Natlonal Laboratory report LA-10235-MS (Januery, 1985). 